\title{
Removing Cryptosporidium-size microspheres with polyaluminium $\mathrm{FeCl}_{3}$
}

\author{
Tao Yuan ${ }^{\mathrm{a}, \mathrm{b}, \mathrm{c}}$, Ping $\mathrm{Lu}^{\mathrm{b}, *}$ \\ ${ }^{a}$ Department of Architecture Equipment and Civil Engineering, \\ Jiangsu Vocational Institute of Architectural Technology, Xuzhou, 221116, China \\ b Department of Environmental Science and Spatial Informatics, \\ China University of Mining and Technology, Xuzhou, 221000, China \\ c JiangSu Collaborative Innovation Centre for Building Energy Saving and Construct Technology, Xuzhou, \\ 221116, China
}

*Corresponding author, e-mail: plu@cumt.edu.cn

Received $14 \mathrm{Feb} 2015$

Accepted 4 Mar 2016

\begin{abstract}
Cryptosporidium is a genus of protozoa that infects swimming pools causing diarrhoea and other illnesses. In this study, the removal of Cryptosporidium-size microspheres from a 100001 swimming pool was evaluated under varying conditions to provide a reliable and efficient water treatment technique. The baseline condition without coagulation (widely practised in swimming pools today) showed that treating a pool with microspheres at a density of 4000 microspheres per litre through a $33 \mathrm{~cm}$ diameter sand filter at $30 \mathrm{~m} / \mathrm{h}$ flow rate removes $25 \%$ of Cryptosporidiumsize microspheres. The filtration followed by polyaluminium $\mathrm{FeCl}_{3}$ (PAFC) coagulation results in $99 \%$ microsphere removal over the $168 \mathrm{~h}$ experimental period with filter backwashing every $48 \mathrm{~h}$. Additionally, the impact of the flow rate and filter cross-sectional area was also examined.
\end{abstract}

KEYWORDS: cryptosporidiosis, swimming pool, recreational water treatment, public health

\section{INTRODUCTION}

Cryptosporidiosis is a diarrhoeal illness caused by the infection of the gastrointestinal tract by the protozoan parasite Cryptosporidium spp., which can last for days or up to $2-3$ weeks ${ }^{1}$. Multiple sources have indicated that infants, young children, pregnant women, and elderly people are more susceptible $^{2}$. Cryptosporidium has caused large waterborne disease (cryptosporidiosis) outbreaks and emerged as a parasite of major public health concern in the US, the UK, and Australia ${ }^{3}$. In 1988, 60 cases of cryptosporidiosis occurred in Los Angeles County, USA $^{4}$. In 1990, an outbreak of cryptosporidiosis occurred in British Columbia, Canada ${ }^{5}$. In 2005, more than 4000 swimmers were infected in New York, nearly 2000 more in Utah in the summer of 2007, and at least 378 others in the Dallas area in the summer of $2008^{4}$. All these outbreaks call for a reliable and efficient swimming pool water treatment technique in response to the public health concerns.

Cryptosporidium spp. are unicellular parasites that infect human epithelial cells of the small intestine, with diameter of 4-6 $\mu \mathrm{m}$, commonly found in lakes and rivers. Cryptosporidium oocysts are environmentally persistent and very resistant to many disinfectants, including chlorine, which is the major barrier to infectious disease transmission that has been used for the past several decades in swimming pool water treatment ${ }^{6}$. Typical swimming pools require at least $1 \mathrm{mg} / \mathrm{l}(\mathrm{ppm})$ free residual chlorine. This free chlorine concentration enables 99.9\% of Cryptosporidium to become inactive for over 11 days $^{6}$. Amburgey reported the sand filter with a thin layer of perlite media on top could remove $98 \%$ of Cryptosporidium-size microspheres at a filtration rate of $49 \mathrm{~m} / \mathrm{h}$ from the pool, which was one of the few studies associated with removal of Cryptosporidium from the swimming pools, and could help reduce outbreaks of cryptosporidiosis ${ }^{7}$. However, adding perlite on top of the filter might increase head loss and require to add new media after each filter backwash.

Conventional water treatment with coagulation and filtration to remove Cryptosporidium from drinking water has been reported ${ }^{8}$. However, coagulation is not typically conducted in swimming pools. Furthermore, swimming pool water treatment is different from that of drinking water. Filters 
are operated in drinking water treatment using four to five times lower filtration rate than at swimming pool facilities $(5-10 \mathrm{~m} / \mathrm{h}$ rather than $20-50 \mathrm{~m} / \mathrm{h}$ ), providing a higher probability of particles colliding and adhering to the filter media. Besides, continuous water circulation in a pool, as well as the continuous organic compounds and microorganisms loading by bathers lead to more complex conditions ${ }^{4}$.

This study evaluated the high-rate filtration followed by coagulation and discussed main infection parameters including the infection of coagulation concentration versus Cryptosporidium-size microspheres concentration as well as filter crosssectional area versus flow rate. The performances of the representative operation (without coagulation) in real-world swimming pools and the novel operational procedure for pools under the swimming pool condition were compared to produce reliable results applicable to real-world swimming pools. Swimming pool condition refers to water that circulates continuously through the filter with high filtration rate relative to drinking water treatment; organic compounds and contaminants continuously circulate in the pool, and cannot be efficiently removed; and typical $\mathrm{pH}$ is controlled in the range of 7.2-7.8 .

\section{MATERIALS AND METHODS}

A 100001 swimming pool was built with filtration system and chemical control system. Pool water can be pumped through the filter (Fig. 1). The sand filter was made from transparent polyvinyl chloride (PVC) pipe. The PAFC solution and microspheres were fed into the pipe right in front of the circulation pump for a rapid coagulant mixing. PAFC is a combined coagulant of polyaluminium chloride (PAC) and polymerization $\mathrm{FeCl}_{3}$ with stoichiometric formula $\left[\mathrm{Al}_{2}(\mathrm{OH})_{n} \mathrm{Cl}_{6-n}\right]_{m} \cdot\left[\mathrm{Fe}_{2}(\mathrm{OH})_{N} \mathrm{Cl}_{6-N}\right]_{M}$. PAFC coagulant solution was made by diluting PAFC with deionized water in a ratio $1 / 15(w / w)$. The simulated swimming pool water was applied in all experiments. A volume of 100001 of local tap water was supplemented with $\mathrm{NaHSO}_{4}, \mathrm{CaCl}_{2}$, and $\mathrm{NaHCO}_{3}$ to adjust to pool water chemical characteristics: $\mathrm{pH}=7.4$, alkalinity $=100 \mathrm{mg} / \mathrm{l}$, hardness $=$ $200 \mathrm{mg} / \mathrm{l}$, free chlorine $=1 \mathrm{mg} / \mathrm{l}$.

Experiments were conducted to determine the potential impact of filter media cross-sectional area and flow rate on microsphere removal using the sand filter. Flow rate and corresponded filter diameter is shown in Table 1. Flow rate varied with the filter cross-sectional area, since the turnover time should be $4 \mathrm{~h}$ for the pool. Filtration rate between,

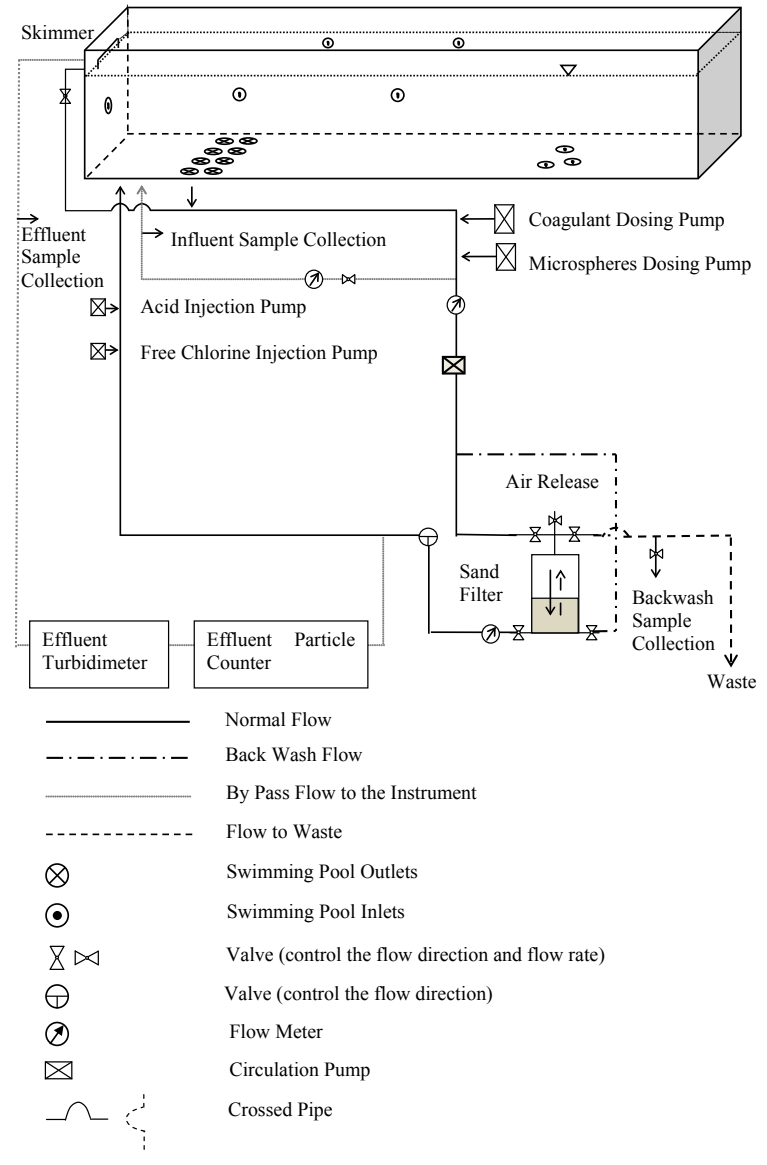

Fig. 1 Swimming pool set-up, 100001.

Table 1 Experimental parameters design based on $4 \mathrm{~h}$ turnover.

\begin{tabular}{lcccc}
\hline & Exp 1 & $\operatorname{Exp} 2$ & $\operatorname{Exp} 3$ & $\operatorname{Exp~4}$ \\
\hline Flow rate $\left(\mathrm{m}^{3} / \mathrm{m}^{2} / \mathrm{h}\right)$ & 20 & 30 & 40 & 50 \\
Filter cross-section $\left(\mathrm{m}^{2}\right)$ & 0.125 & 0.085 & 0.071 & 0.049 \\
Filter diameter $(\mathrm{cm})$ & 40 & 33 & 30 & 25 \\
\hline
\end{tabular}

$20-30 \mathrm{~m} / \mathrm{h}$ was medium-rate and $30-50 \mathrm{~m} / \mathrm{h}$ was high-rate filter operation for the pool.

Coagulant dose may impact the overall removal. A constant sand filter cross-sectional area $(33 \mathrm{~cm}$ diameter) and flow rate $(30 \mathrm{~m} / \mathrm{h})$ was applied in all experiments. Seeding of the coagulant and microspheres simultaneously and continuously was conducted. The experiment was performed in $48 \mathrm{~h}$ (12 turnovers) and samples were collected every $4 \mathrm{~h}$.

Paired experiments with and without filter backwash were conducted over seven days (168 h) in order to test the impact of backwash on system 
performance and to evaluate the long time system performance. Experiments were also performed with addition of coagulant. Backwash was conducted every $48 \mathrm{~h}$ and samples were collected at every turnover.

The use of polystyrene microspheres as an oocyst surrogate has been done by multiple researchers and was used in this study ${ }^{9}$. Microspheres with diameter of $4.5 \mu \mathrm{m}$ were used as the surrogate since microspheres are virtually identical to Cryptosporidium oocysts in size, shape, density, and surface charge in pool water. Microsphere samples were mixed by vortexing and hand shaking for at least $2 \mathrm{~min}$ each before analysing. Samples were passed through $3.0 \mu \mathrm{m}$ pore size polycarbonate filters. Each polycarbonate filter was mounted on a glass microscope slide with a polyvinyl alcoholDABCO solution, covered with a glass cover slip, and microspheres were counted under an epifluorescence microscope ${ }^{10}$. For ease of counting and to obtain statistically valid data, microscope slides needed to contain between 10 and 150 microspheres. Removal efficiency was calculated by comparing the concentrations between the influent and the effluent samples.

A control experiment was conducted without filter media to test if there were microsphere losses in the system. The average 1\% removal rate (approximately zero) was obtained and a virtually insignificant system loss was demonstrated. Cryptosporidium-size microspheres removed by the $30 \mathrm{~cm}$ depth sand filter at $30 \mathrm{~m} / \mathrm{h}$ without coagulation was conducted for $24 \mathrm{~h}$ as another control experiment. Duplicate experiments were conducted, while triplicate samples in each experiment were taken. The swimming pool was rinsed, filled, and drained with tap water at least three times between experiments to limit the amount of cross-contamination between experiments. Fresh sand was used for each experiment. Sand filter was backwashed with simulated pool water for $5 \mathrm{~min}$ to ensure the sand was clean and sand grains restratified (fine grains on top and coarse grains on bottom).

\section{RESULTS}

As indicated before, filter media cross-sectional area and flow rate should be adjusted in different direction to maintain a 4-h pool turnover, thus an increase in the flow rate would lead to a decreased cross-sectional area, provided that the turnover is unchanged. Microsphere removals under four different experimental conditions (different sand cross-sectional areas and flow rates) were evaluated

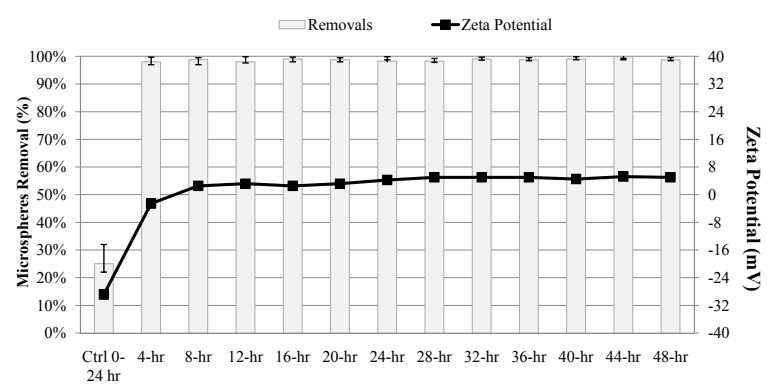

Fig. 2 Microsphere removals under different experimental conditions.

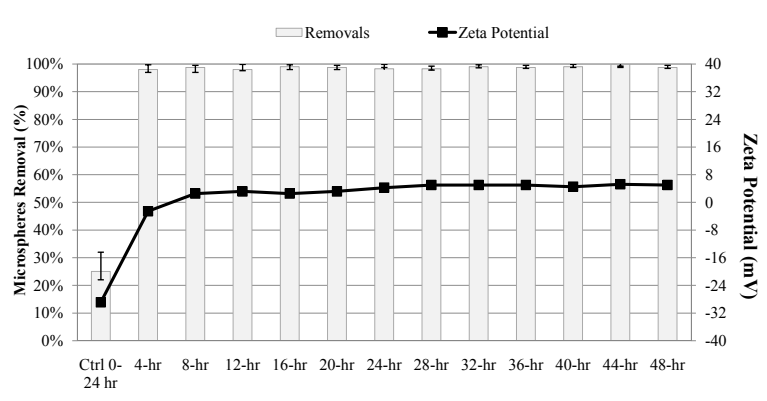

Fig. 3 Cryptosporidium-size microsphere removals and $\zeta$ potential variation, $0-48 \mathrm{~h}, 33 \mathrm{~cm}$ diameter sand, flow rate $30 \mathrm{~m} / \mathrm{h}$.

(Fig. 2). Approximate $99 \%$ of microspheres were removed by $40-\mathrm{cm}$ diameter filter at $20 \mathrm{~m} / \mathrm{h}$ and $33-$ $\mathrm{cm}$ diameter filter at $30 \mathrm{~m} / \mathrm{h}$. Microsphere removals decreased with higher flow rate and smaller filter cross-sectional area. Removals were significantly decreased $(<90 \%)$ when the flow rate was $30 \mathrm{~m} / \mathrm{h}$ (or higher) and the filter diameter was $33 \mathrm{~cm}$ (or less).

Percent removal of Cryptosporidium-size microsphere and $\zeta$-potential of samples with/without coagulation in $48 \mathrm{~h}$ are shown in Fig. 3. Control experiment without coagulant, simulation of today pool water treatment, only achieved $22 \%$ to $32 \%$ microsphere removals through $33-\mathrm{cm}$ diameter sand filter at $30 \mathrm{~m} / \mathrm{h}$. However, the removal efficiency from $97 \%$ to $99.9 \%$ was achieved by continuous inputs of coagulant at the same operation condition as the control. Results indicated PAFC should be fed continuously to maximize the removal of Cryptosporidium-size microspheres from the pool. The $\zeta$-potential was $-29 \mathrm{mV}$ for the control without coagulation and increased with the addition of the coagulant. The rest of $\zeta$-potentials of the samples were between -2.6 and $5.3 \mathrm{mV}$, which was in the range of $-10 \mathrm{mV}$ and $+10 \mathrm{mV}$, the favourable condition for particle removal ${ }^{11}$. 


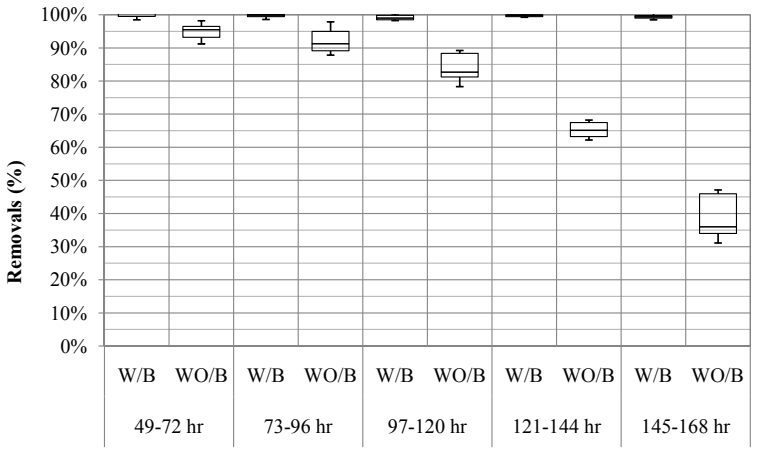

Fig. 4 Microsphere removals with coagulant under conditions with backwash (W/B) and without backwash (WO/B), 48-168 h, $33 \mathrm{~cm}$ diameter sand, and $30 \mathrm{~m} / \mathrm{h}$ flow rate.

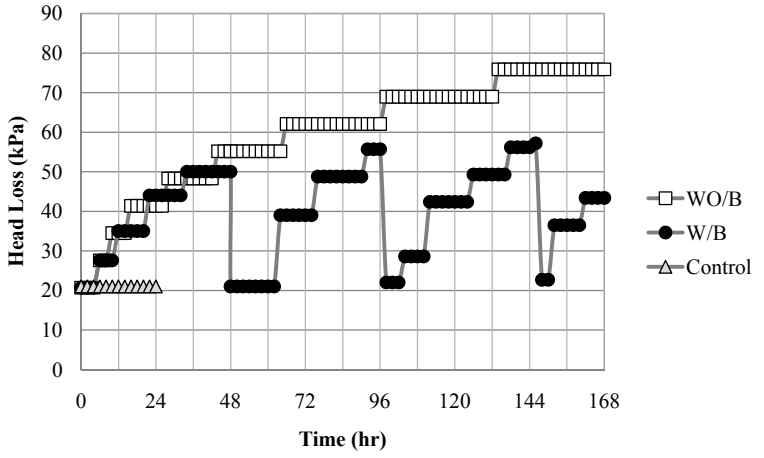

Fig. 5 Head loss variation over time, 0-168 h, (W/B: with backwash and coagulation, WO/B: without backwash but with coagulation, control: without coagulation), $33 \mathrm{~cm}$ diameter sand, and $30 \mathrm{~m} / \mathrm{h}$ flow rate.

Fig. 4 compares removals with/without filter backwash every $48 \mathrm{~h}$. Results showed backwash filter every $48 \mathrm{~h}$ achieved stable microsphere removals (97-99\%) in 168 h (7 days). However, microsphere removals dropped over time without backwash. Head loss variations are shown in Fig. 5. For experiment without backwash, the head loss increased from 20-76 kPa in $168 \mathrm{~h}$. For experiment with backwash, the head loss fluctuated in $168 \mathrm{~h}$, which rose over time and dropped after backwash. The peaks went up as much as $57 \mathrm{kPa}$ from the baseline pressure of approximately $20 \mathrm{kPa}$ at the bottom of the filter. Results showed removals decreased with the rising head loss, which indicated the larger the head loss was, the lower the removal was under the experimental condition.

Effluent turbidity variation over $168 \mathrm{~h}$ is shown in Fig. 6. Control experiment barely removed turbidity as seen in Fig. 6 . The effluent turbidity

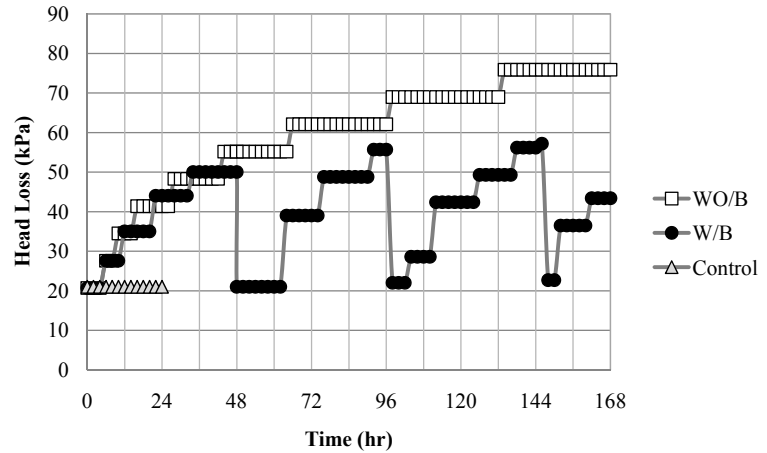

Fig. 6 Effluent turbidity variation over time, 0-168 h, $33 \mathrm{~cm}$ diameter sand, and $30 \mathrm{~m} / \mathrm{h}$ flow rate.

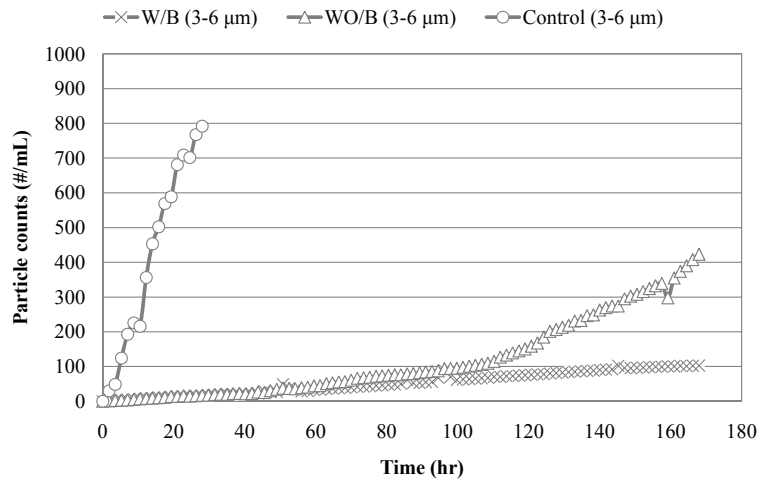

Fig. 7 Effluent particles (3-6 $\mu \mathrm{m}$ ) variation over time, 0-168 h, $33 \mathrm{~cm}$ diameter sand, and $30 \mathrm{~m} / \mathrm{h}$ flow rate.

decreased from 2.2 to $1.3 \mathrm{NTU}$ in $7 \mathrm{~h}$ and stable at 1.3 NTU. However, much lower effluent turbidity was observed with an addition of PAFC per turnover.

Effluent particle count variations are shown in Fig. 7. The 3-6 $\mu \mathrm{m}$ particle counts went up over time since $4.5 \mu \mathrm{m}$ microspheres were continuously added. There were many more 3-6 $\mu \mathrm{m}$ particles for the control, comparing the experiments with coagulation because most of the particles were accumulating in the pool. Effluent particle count profiles for experiment with coagulation and backwash were nearly a straight line, and there were three peaks after backwash just similar to the turbidity variation profile. The increased 3-6 $\mu \mathrm{m}$ particle counts showed decreased microsphere removals. Particle counts between 7 and $20 \mu \mathrm{m}$ were less than 20 microspheres $/ \mathrm{ml}(\# / \mathrm{ml})$ and did not significantly change during the three experiments. The results imply that the particle counters were more sensitive to changes in pool water system compared with turbidities. 


\section{DISCUSSION}

Comparing with today's pool treatment, simulated by control experiment, only $22 \%$ to $32 \%$ of microspheres were removed, 97-99\% (or even 99.9\%) of Cryptosporidium-size microspheres were removed through high-rate filtration $(30 \mathrm{~m} / \mathrm{h})$ and continuous feeding PAFC into the pool with backwashing filter every other day. The enhanced performance was due to the suspension being destabilized by PAFC prior to pool water passing through the filter. The removals of Cryptosporidium have been reported to be dependent on the Cryptosporidium oocyst concentration in the source water and corresponding coagulant dosage ${ }^{12}$.

In terms of microsphere removals decreasing with increased flow rate and decreased filter crosssectional area, the reasons included: (1) larger surface area tended to capture more particles and the amount of increasing media led to greater removals; (2) the lower flow rate could lead to the higher removals due to less shearing actions within the filter pores, which decreased the transport of particle matters through the filter bed. Proper flow rate and filter cross-sectional area with adequate coagulation in a given turnover time should therefore be discussed for pools.

Head loss increased during experiment, which was due to the particles were entrapped and deposited on the surface and interstices of the filter media. Thus pore spaces of filter were reduced and filter resistance increased. Thus regular backwashing should be conducted to deal with filter head loss increased and microsphere removals declined over time. Turbidity peaks after filter backwashes and return to normal in a short time.

Acknowledgements: The authors wish to thank the National Natural Science Foundation of China (41 403 090), and the Foundation of JiangSu Collaborative Innovation Centre for Building Energy Saving and Construct Technology (SJXTY1507).

\section{REFERENCES}

1. Mead JR (2002) Cryptosporidiosis and the challenges of chemotherapy. Drug Resist Updates 5, 47-57.

2. Hoxie NJ, Davis JP, Vergeront JM, Nashold RD, Blair KA (1997) Cryptosporidiosis-associated mortality following a massive waterborne outbreak in Milwaukee, Wisconsin. Am J Publ Health 87, 2032-5.

3. Lisle JT, Rose JB (1995) Cryptosporidium contamination of water in the USA and UK: a mini review. J Water Supply Res Tech Aqua 44, 103-17.
4. Lu P, Yuan T, Feng Q, Xu A, Li J (2013) Review of swimming-associated cryptosporidiosis and Cryptosporidium oocysts removals from swimming pools. Water Qual Res J Can 48, 30-9.

5. Bell A, Guasparini R, Meeds D, Mathias RG, Farley JD (1993) A swimming pool-associated outbreak of cryptosporidiosis in British Columbia. Can $\mathrm{J} \mathrm{Publ}$ Health 84, 334-7.

6. Korich D, Mead J, Madore M, Sinclair N, Sterling C (1990) Effects of ozone, chlorine dioxide, chlorine, and monochloramine on Cryptosporidium parvum oocyst viability. Appl Environ Microbiol 56, 1423-8.

7. Amburgey J (2011) Removal of Cryptosporidiumsized polystyrene microspheres from swimming pool water with a sand filter with and without added perlite filter media. J Environ Eng 137, 1205-8.

8. Edzwald JK, Kelley MB (1998) Control of Cryptosporidium: from reservoirs to clarifiers to filters. Water Sci Tech 37, 1-8.

9. Amburgey JE, Amirtharajah A, Brouckaert BM, Spivey NC (2004) Effect of washwater chemistry and delayed start on filter ripening. J Am Water Works Assoc 96(1), 97-110.

10. Freer SM (1984) A permanent wet-mount for fluorescent microscopy of surface stained lymphoid cells. J Immunol Meth 66, 187-8.

11. Tseng T, Segal BD, Edwards M (2000) Increasing alkalinity to reduce turbidity. J Am Water Works Assoc 92(6), 44-54.

12. Betancourt WQ, Rose JB (2004) Drinking water treatment processes for removal of Cryptosporidium and Giardia. Vet Parasitol 126, 219-34. 